\title{
Resistances to Turnip Mosaic Potyvirus in Arabidopsis thaliana
}

\author{
África Martín Martín, Héctor Luis Cabrera y Poch, David Martínez Herrera, and Fernando Ponz \\ INIA, Dpto. Mejora Genética y Biotecnología, Autopista A-6, Km 7, 28040 Madrid. Spain \\ Accepted 22 July 1999.
}

\begin{abstract}
The responses of a collection of Arabidopsis thaliana ecotypes to mechanical inoculation with turnip mosaic potyvirus were assessed. The virus induced characteristic severe symptoms of infection in systemically infected plants. Resistance was found in four ecotypes: Bay-0, Di-0, Er-0, and Or-0. Enzyme-linked immunosorbent assay results of the resistant ecotypes suggested that ecotypes Di-0, Er-0, and Or-0 actually consist of mixed genotypes with resistances acting at different levels in the virus life cycle. Another form of resistance was found in ecotype Bay-0, for which several lines of evidence indicated an interference with viral cell-to-cell movement in the inoculated leaves.
\end{abstract}

Plant model systems allow the development of reference points regarding fundamental hypotheses and models in many areas of plant biology. One of these areas deals with the study of the different types of interactions that can be established between a plant and a viral pathogen. The economic impact of the infection of crop plants by viruses has been a major driving force in the development of plant virology as a discipline (Agrios 1997; Brunt et al. 1996). At present, characterization of the role of virus gene products in the infection processes is much better than that of the plant factors involved in the interaction (Agrios 1997; Crute et al. 1997 ). For this reason, in the last few years the plant model system Arabidopsis thaliana has become a favorite for many research groups involved in the characterization of the plant side of the interaction with pathogens, including viruses (Kunkel 1996).

Potyviruses form the largest family of plant virus pathogens and economic losses induced by them are significant worldwide (Shukla et al. 1994). Potyviruses are single-stranded (+) RNA viruses whose virions are flexuous rods. The potyviral gene expression strategy occurs via the viral-controlled proteolytic processing of a single polyprotein precursor (Riechmann et al. 1992). The role of the different viral-encoded

Corresponding author: Fernando Ponz; INIA, Dpto. Mejora Genética y Biotecnología, Autopista A-6, Km 7, 28040 Madrid, Spain; Telephone: + 3491 3476887; Fax: + 3491 3573107; E-mail: fponz@inia.es

Current address of África Martín Martín: Department of Medical Biochemistry and Microbiology, Unit of Biochemistry, Biomedical Centrum (BMC), Husargatan 3, Box 575, SE-751 23 Uppsala, Sweden.

Current address of Héctor Luis Cabrera y Poch: Department of Plant Biology, Genetic Centre, SLU, S-75007 Uppsala, Sweden. proteins has been the topic of intense research efforts in the last decade (Kasschau et al. 1997; Schaad et al. 1997; and references cited therein).

We have previously identified turnip mosaic virus (TuMV) as a potyvirus able to systemically infect Arabidopsis thaliana (Martínez-Herrera et al. 1994). Tobacco etch virus (TEV), another potyvirus, also infects $A$. thaliana and sources of resistance have been identified to TEV in this species (Mahajan et al. 1998). TuMV has been ranked among the five most damaging vegetable viruses worldwide (Tomlinson 1987). The virus is extremely variable in its pathogenic and serological properties. Classification of a large collection of TuMV isolates into pathotypes according to their behavior in Brassica spp. has been proposed recently (Jenner and Walsh 1996). The translational initiation factor (iso) $4 \mathrm{E}$ of $A$. thaliana has been shown to interact specifically with the viral protein VPg (Wittmann et al. 1997). Several infectious cDNA clones of the type member of the pathotype 1 of TuMV, isolate UK-1, have been synthesized recently (Sánchez et al. 1998). As a necessary first step to gain an insight into plant functions involved in the potyvirus infection process, we describe in this paper the type of variability found in the interactions between the isolate UK-1 of TuMV and a large collection of A. thaliana ecotypes.

A collection of 106 ecotypes of A. thaliana, obtained from the Arabidopsis Seed Bank and from C. Somerville (Stanford University) was used for the initial screening. Prior to virus inoculation, seeds and plants were treated essentially as previously described (Martín Martín et al. 1997). Isolate UK-1 of TuMV, pathotype 1 (Tomlinson and Ward 1978; Jenner and Walsh 1996), was maintained by serial passages in plants of the susceptible $A$. thaliana ecotype Bs- 1 . The virus inoculum for the ecotype screening consisted of freshly prepared crude sap from TuMV UK-1 Bs-1 infected plants, obtained and used as described for oilseed rape mosaic virus (ORMV; Martín Martín et al. 1997). This type of inoculum was chosen instead of purified virus coming from different preparations for practical reasons of simplicity and reproducibility. Purified potyvirus virions are difficult to store long-term without a substantial loss of infectivity of the preparations (Brunt 1988). Some attempts to use such preparations showed this problem in the preliminary screenings.

Standard antigen-coated indirect enzyme-linked immunosorbent assay (ELISA; Koenig 1981) was used to analyze the inoculated plants 25 days after inoculation. A commercial 
anti-potyvirus monoclonal antibody kit (Agdia, Elkhart, IN) was used, following the conditions recommended by the manufacturer. The reaction of the substrate ( $p$-nitrophenyl phosphate) was followed at $405 \mathrm{~nm}$. Three different molecular approaches were used to evaluate the presence of accumulated viral RNA in plant tissue. (i) Plant skeleton hybridizations on whole A. thaliana plants were performed essentially as described (Leisner et al. 1992; Simon et al. 1992) with slight modifications. (ii) Northern (RNA) blot hybridization analyses (Sambrook et al. 1989) were performed on total RNA extracted from plant tissue. Equal amounts $(1 \mu \mathrm{g})$ of denatured RNA samples were loaded and run in a formaldehyde-agarose gel, transferred to Hybond $\mathrm{N}^{+}$membranes (Amersham, Little Chalfont, UK), hybridized at $65^{\circ} \mathrm{C}$ to a radiolabeled (Megaprime kit, Amersham) 515-bp cDNA fragment of the TuMV coat protein gene, obtained by immunocapture-reverse transcription-polymerase chain reaction (IC-RT-PCR, see below), and washed under highly stringent conditions. (iii) Detection of accumulated viral RNA in the total RNA preparations was performed by standard RT-PCR (Sambrook et al. 1989). IC-RT-PCR was carried out as previously described for potyviruses and other RNA plant viruses (Nolasco et al. 1993). Specific primers: $3^{\prime}$-(5'-ATGTATGGTCGGTCTTGGT TAC-3') and $5^{\prime}-\left(5^{\prime}\right.$-AGAGAAGGCAGAAAAGGAACGA$\left.3^{\prime}\right)$, corresponding to positions 69 to 584 of TuMV-coat protein sequence (Lehmann et al. 1997), were used to amplify a TuMV-specific, 515-bp cDNA fragment.

Protoplasts were obtained from leaves of A. thaliana plants that had been inoculated with TuMV. The protoplast preparations were done either 8 days after inoculation (protoplasts from inoculated leaves) or 21 days after inoculation (noninoculated leaves). The overall protoplast preparation and immunochemical analysis were essentially as previously described for pepper protoplasts (Arroyo et al. 1996).

Symptoms that developed in infected plants of any susceptible ecotype were similar and included plant stunting and developmental arrest, leaf mosaic, sawed and curly leaves, and aborted flowers (Fig. 1). No necrotic lesions were seen on any

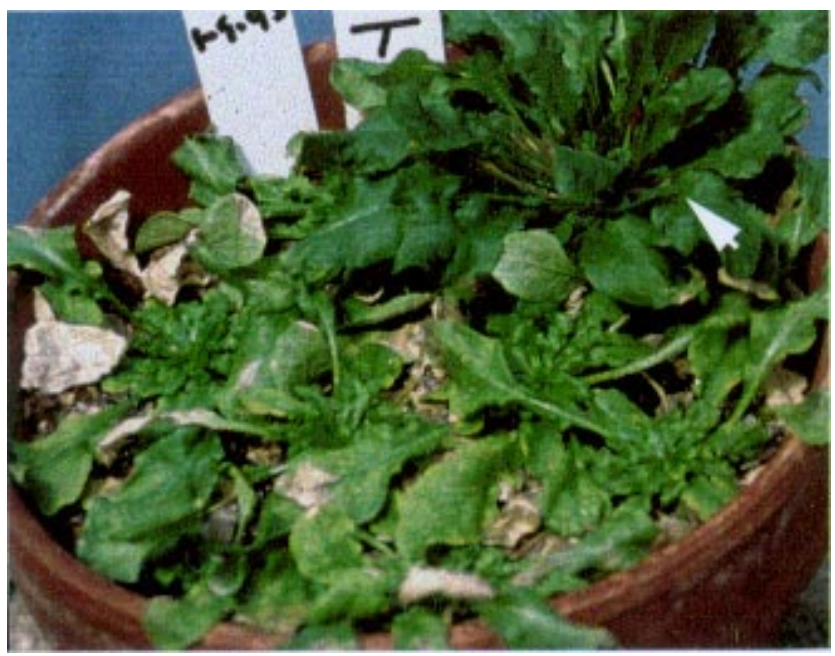

Fig. 1. Symptoms induced by turnip mosaic virus (TuMV)-UK1 in Arabidopsis thaliana plants. Sixteen-day-old plants of ecotype Do-0 were mechanically inoculated with TuMV-UK1. Arrowhead points to a mock-inoculated control plant. Picture was taken about 3 weeks after inoculation. ecotype. The presence of visible symptoms in infected plants corresponded to a positive reading in ELISA (data not shown). Different ecotypes showed different percentages of infected plants, however. Individual plants that did not become infected after the first inoculation were reinoculated with the same type of inoculum, but no new infections were observed. Only 37 out the 106 ecotypes showed a homogeneous response. The remaining 69 ecotypes presented different percentages of infected plants, ranging from nearly total infection (>90\% infection rate) to nearly total resistance (around 10\% infection rate). For this reason, all ecotypes analyzed were classified arbitrarily into three groups according to the percentage of individuals within ecotypes susceptible to TuMV infection (Table 1). The ecotypes in group III showed resistance to virus infection. In no plants of those ecotypes did we find symptoms of virus infection. ELISAs performed on noninoculated leaves to determine whether systemic infection had occurred were negative (not shown).

The resistance found in the ecotypes in group III was further characterized. At least 200 plants of each ecotype were inoculated with TuMV UK-1. ELISAs were performed for all of them, differentiating inoculated and noninoculated leaves. The same number of plants of ecotype Bs-1 (group I) were processed in parallel as a positive control. Approximately two-thirds of the plants of ecotypes Er- 0 , Or- 0 , and Di- 0 gave negative ELISA results both in inoculated and noninoculated leaves, indicating the absence of detectable levels of accumulated coat protein. The remaining one-third of the plants were ELISA positive, but only in the inoculated leaves, revealing a considerable amount of virus accumulation. This result suggests that different forms of resistance to the virus can be found in these resistant ecotypes, indicating the presence of variability for this trait within the ecotype. In contrast to the other three ecotypes, all plants of ecotype Bay-0 were negative by ELISA, either in inoculated or noninoculated leaves, 10 to 12 days after inoculation. Thus, ecotype Bay- 0 behaved as a homogeneous genotype for resistance to infection by TuMV UK-1.

The resistance found in Bay- 0 was characterized by several different approaches. The sensitivity of the ELISA used was

Table 1. Classification of Arabidopsis thaliana ecotypes according to TuMV-UK1 infections ${ }^{\mathrm{a}}$

\begin{tabular}{|c|c|c|}
\hline Group & $\begin{array}{l}\text { Infected } \\
\text { plants }(\%)\end{array}$ & Ecotypes \\
\hline I & 100 & $\begin{array}{l}\text { Bd-0, Be-1, Bor-0, Br-0, Bs-1, Can-0, Chi-0, } \\
\text { Cit-0, Cl-0, Ct-1, Da-0, Db-1, Do-0, Eil-0, Fe-1, } \\
\text { Ha-0, Is-0, Kil-0, La-er-, Lu-1, Lz-0, Mr-0, } \\
\text { Mrk-0, Np-0, Ob-0, Old-1, Oy-0, Pf-0, Pr-0, } \\
\text { Sue-0, Te-0, Uk-1, W1-0 }\end{array}$ \\
\hline II & 1 to 99 & $\begin{array}{l}\text { Aa-0, Ag-0, Ak-1, An-1, Ang-0, Bch-1, B1-1, } \\
\text { Bn-0, Bsch-0, Bus-0, Ca-0, Cal-0, Ci-0, Co-1, } \\
\text { Col-0, Cvi-0, Dr-0, Edi-0, Ei-2, El-0, En-1, Ep- } \\
\text { 0, Et-0, Fi-0, Fr-2, Fr-3, Gd-1, Gr-1, Gü-0, Gy- } \\
\text { 0, Hau-0,Hi-0, Hs-0, Kä-0, Kb-0, Ko-2, Kr-0, } \\
\text { Li-1, Lip-0, Lm-0, Ma-0, Mc-0, Me-0, Mt-0, } \\
\text { Mz-0, Nc-1, Nd-0, No-0, Nw-0, Ove-0, Per-1, } \\
\text { Pi-0, Pn-0, Po-0, Pt-0, Rd-0, RLD, Rsch-0, Sah- } \\
\text { 0, Se-0, Set-0, Sp-0, Ste-0, Stw-0, Tsu-0, Tul-0, } \\
\text { Ty-0, Wc-1, Ws-0 }\end{array}$ \\
\hline III & 0 & Bay-0, Di-0, Er-0, Or-0 \\
\hline
\end{tabular}

${ }^{a}$ Indirect enzyme-linked immunosorbent assay (ELISA; anti-potyvirus antibody) was performed on noninoculated leaves of inoculated plants. 
not sufficient to discard a low level of virus multiplication. In other situations, plant skeleton hybridization has been used in virus-inoculated Arabidopsis plants to visualize infection foci (Simon et al. 1992; Lartey et al. 1998). Thus, we performed this type of assay on the Bay-0 plants. As shown in Figure 2, we did not detect any hybridization signal with the viralderived, radioactive probe in skeletons of Bay-0 plants in either inoculated or noninoculated leaves at 3 or 10 days after virus inoculation (Fig. $2 \mathrm{C}$ and D). This time period was sufficient to detect virus accumulation locally and systemically in skeletons of Bs-1 plants used as controls (Fig. 2B).

Total RNA from TuMV UK-1 inoculated leaves of Bay- 0 was isolated 8 days after virus inoculation, and used in Northern blot hybridization analysis. Again, Bs-1 plants were used as controls. After only $3 \mathrm{~h}$ of film exposure of the blot hybridized to a radiolabeled viral cDNA probe, the autoradiograph gave a strong hybridization signal at the position corresponding to the mobility of TuMV RNA $(9.6 \mathrm{~kb})$ in the lane of susceptible ecotype Bs-1 (Fig. 3A), whereas no signal was
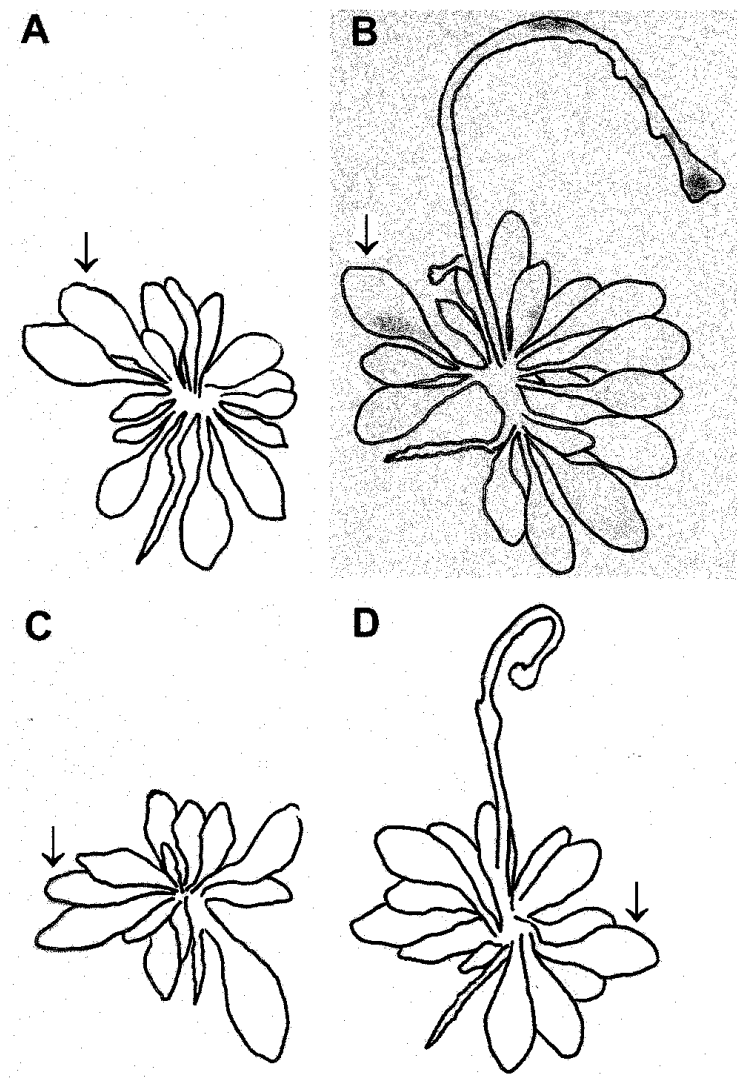

Fig. 2. Hybridizations of Arabidopsis thaliana plant skeletons with a turnip mosaic virus (TuMV)-specific probe. Skeletons of A. thaliana plants of ecotypes (A and B) Bs-1 and (C and D) Bay-0 were hybridized with a radioactive TuMV cDNA probe and film-exposed. Plant skeletons prepared (A and $\mathbf{C}) 3$ and (B and D) 10 days after inoculation. Shapes of skeletons were pen-drawn on film to help in identification of signal localization. Arrows indicate inoculated leaves. B, Hybridization signals are only visible in some parts of skeleton corresponding to Bs-1 plants 10 days after inoculation. detected in the lane corresponding to the resistant ecotype Bay-0. However, when the same filter was overexposed (Fig. 3B), a faint band was observed in the lane of ecotype Bay-0 plants at the same position as for ecotype Bs-1. The mockinoculated plants did not show any signal after 5 days of exposure (Fig. 3B). A quantitative comparison was done between signals of Bay- 0 and Bs- 1 plants, with electronic image analysis. After the appropriate corrections considering differences in exposure time (see Figure 3 caption), we estimated a 135-fold approximate difference in the level of accumulation between both ecotypes. This result strongly suggests that some very low level of virus replication and accumulation occurred in the inoculated leaves of Bay-0 plants. To confirm this suggestion, RT-PCR was performed on all three (virusinoculated Bs-1 and Bay-0, and mock-inoculated Bay-0) RNA samples with TuMV-specific primers. An RT-PCR amplified cDNA fragment of the expected length (515 bp) was observed in the lanes corresponding to TuMV-inoculated Bs-1 and Bay0 plants (Fig. 3C). No band was amplified in the control mock-inoculated Bay-0 sample. The possibility of a low level of virus accumulation (undetectable by Northern blot analysis) in the noninoculated leaves of TuMV-inoculated Bay-0 plants was tested by IC-RT-PCR. We did not detect any amplification band in extracts of Bay-0, whereas the corresponding 515-bp band was amplified in Bs-1 extracts (results not shown).

The above results obtained for ecotype Bay- 0 are consistent with the conclusion that TuMV UK-1 is not able to invade the plant to produce a systemic infection under the conditions of the experimental system used. On the other hand, the faint signal obtained in the Northern blot hybridization analysis of the inoculated leaves and the band obtained after TuMVspecific, RT-PCR amplification in RNA samples from these leaves were indicative of a low level of virus replication and accumulation in the inoculated leaves. However, from these results we cannot exclude the possibility either that the viral RNA detected in these experiments corresponded to undegraded RNA from the virus inoculum used or that some inhibition of encapsidation or movement of this RNA was occurring, perhaps due to the lack of coat protein accumulation. Thus, we analyzed virus accumulation in protoplasts prepared from TuMV UK-1 inoculated A. thaliana plants of Bay-0, and Bs-1 as a control, using virus immunofluorescent detection with a TuMV UK-1 monoclonal antibody. Separated preparations of protoplasts from inoculated and noninoculated leaves were analyzed. The percentages of the different protoplast preparations showing fluorescence indicative of virus accumulation are shown in Table 2. Approximately $20 \%$ of the total amount of protoplasts prepared from inoculated leaves of the susceptible Bs-1 ecotype were intense green under the fluorescence microscope. The equivalent preparations from Bay-0 showed about 20 times less fluorescent protoplasts (about $1 \%$ of the total). The fluorescence exhibited by these protoplasts was visually as intense as in Bs-1 protoplasts, indicating that apparently there was not a detectable reduction in coat protein accumulation in these cells, but rather simply fewer infected cells. When protoplast preparations from noninoculated leaves of infected plants were examined, no Bay-0 fluorescent protoplasts were found, whereas more than half the protoplasts were infected in Bs-1 samples. Protoplasts from control mock-inoculated plants of ecotypes Bay-0 or Bs1 gave no background fluorescent signal. 
The absence of difference in fluorescence intensity between infected protoplasts from the susceptible (Bs-1) and the resistant (Bay-0) lines is a strong indication that virus replication and accumulation take place in a small percentage of cells of the inoculated Bay-0 leaves, up to a level comparable to that found in susceptible ecotypes. Taken altogether, these results suggest that the cell-to-cell movement of TuMV UK-1 is strongly interfered with in Bay-0 plants. We (Arroyo et al. 1996) and others (Gibb et al. 1989; Valkonen and Somersalo 1996) have found this form of resistance to a potyvirus in different plant systems. As far as we are aware, none of the natural resistances to viruses described in A. thaliana to date act with this type of mechanism, although recently a chemically induced mutant of ecotype Col- 0 has been obtained that resists infection by cucumber mosaic virus via a similar mechanism (Yoshii et al. 1998). Recent work has shown that the cell-tocell movement of potyviruses is a complicated process involving several virus products (Dolja et al. 1994; Nicolas et al. 1997; Rodríguez-Cerezo et al. 1997; Rojas et al. 1997; Carrington et al. 1998; Roberts et al. 1998). The identification of Bay- 0 as an A. thaliana ecotype interfering with the cell-tocell movement process may provide a useful tool for the eventual identification of plant factors involved in potyvirus movement.

The work in this paper deepens and extends our previous observation that TuMV is a pathogen of Arabidopsis (Martínez-Herrera et al. 1994). Isolate UK-1 of TuMV (Tomlinson and Ward 1978) was chosen because it is the type member of the pathotype 1 of this potyvirus and, as such, several sources of resistance in Brassica spp. are effective against it (Jenner and Walsh 1996). Given the considerable degree of relatedness between Brassica spp. and A. thaliana genomes (Cavell et al. 1998; Conner et al. 1998), we reasoned that the possibility of finding genes for resistance to TuMV in Arabidopsis would be high with this isolate.

Most A. thaliana ecotypes analyzed could be systemically infected with TuMV UK-1, showing severe symptoms without significant differences among the infected individual plants belonging to the different ecotypes. This was in high contrast to the results obtained by us in a parallel study conducted with

Fig. 3. Analysis of viral RNA in resistant ecotype Bay-0. Ecotype Bay-0 and susceptible ecotype Bs-1 plants were inoculated with turnip mosaic virus (TuMV), and total RNA from inoculated leaves was prepared 8 days after inoculation. One microgram of each sample was analyzed by RNA blot hybridization with a ${ }^{32} \mathrm{P}$-labeled, virus-specific probe $(\mathbf{A}, 3 \mathrm{~h}$ exposure; B, 5-day exposure) or (C) subjected to reverse transcriptionpolymerase chain reaction (RT-PCR) with TuMV-specific primers. A and B: Lanes 1-3, samples of mock-inoculated Bay-0, TuMV-inoculated Bay-0, and TuMV-inoculated Bs-1 (positive control) plants, respectively. Arrowheads point to position in gel of TuMV RNA $(9.6 \mathrm{~kb})$. Quantitative comparison between signal intensities from Bs-1 and Bay-0 RNA blot hybridizations was done by image analysis with Lane Manager 2.1 software (TDI, Madrid). Briefly, area of signal in lane 3A was delimited and its color intensity measured. Then, background from the corresponding position in lane 1A was substracted. Value obtained was multiplied by 40 (difference in exposure time); resulting value was divided by number obtained after same procedure for the signal in lane 2B. C, Aliquots of RT-PCR products were analyzed in an agarose gel: lane 1, DNA molecular weight markers; lane 2, empty; lane 3, mockinoculated Bay-0 plants; lane 4, TuMV-inoculated Bs-1 plants; lane 5, TuMV-inoculated Bay-0 plants. Arrowhead points to position in the gel of expected 515-bp product.
Table 2. Percentage of protoplasts showing virus replication in leaves of Arabidopsis thaliana ecotypes Bs-1 and Bay-0 inoculated with turnip mosaic virus (TuMV)-UK1 ${ }^{\mathrm{a}}$

\begin{tabular}{lcccccc}
\hline & \multicolumn{2}{c}{ Bs-1 } & & \multicolumn{2}{c}{ Bay-0 } \\
\cline { 2 - 3 } \cline { 5 - 6 } Leaf type & Buffer & TuMV & & Buffer & TuMV \\
\hline Inoculated leaves & 0 & $20 \pm 2^{\mathrm{b}}$ & & 0 & $1 \pm 0.4^{\mathrm{b}}$ \\
Noninoculated leaves & 0 & 55 & & 0 & 0 \\
\hline
\end{tabular}

${ }^{a}$ Density $4 \times 10^{6}$ protoplats per $\mathrm{ml}$. Viability $80 \%$.

${ }^{\mathrm{b}}$ Values represent average percentage of infected protoplasts \pm standard error. Experiments were conducted four times. In each experiment approximately $10^{5}$ protoplasts were scored.

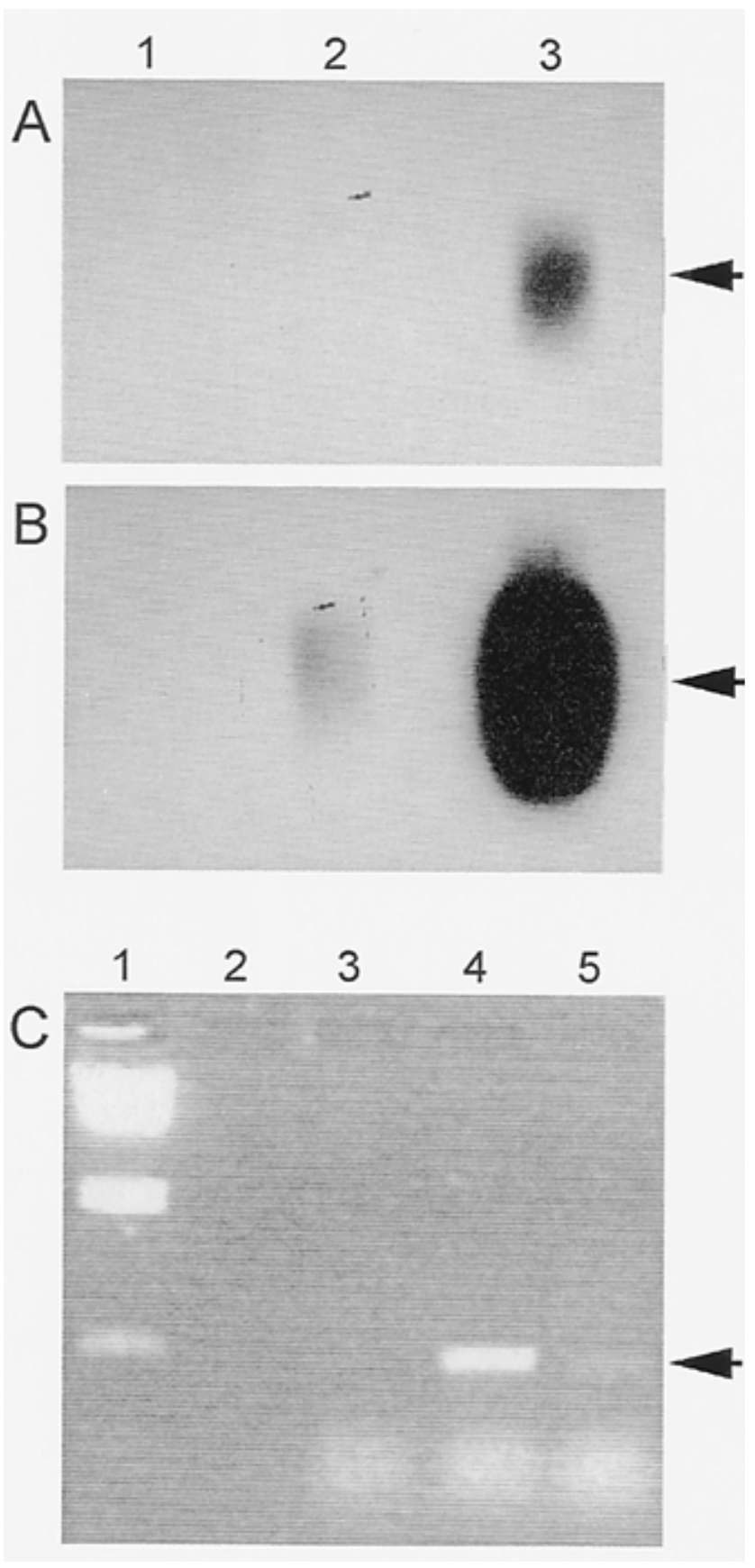


ORMV (Martín Martín et al. 1997). The different results obtained for these two viruses most likely relate to their different extents of dependence on the plant developmental stage to induce symptoms in the infected plants. Developmental resistance was described in A. thaliana for CaMV (Leisner et al. 1993). In addition, by comparison with the results obtained with ORMV, another important difference was that we did not find any TuMV UK-1 tolerant ecotypes.

A puzzling situation was obtained for ecotypes included in group II. Ecotypes in this group exhibited virus resistance upon mechanical inoculation. The percentages of resistant plants varied between ecotypes in the group. Again, this result is in contrast with those obtained for ORMV, where all the individual plants within a given ecotype showed the same type of symptoms and no resistant plants were found in susceptible ecotypes (Martín Martín et al. 1997). There are at least two possible explanations for this finding. (i) The type of inoculum used (crude sap from infected plants) was not sufficiently infectious to establish an infection in all the plants inoculated. However, the same inoculum was able to infect all the plants in many other ecotypes, in some of which, such as Bs-1 or RLD, literally hundreds or thousands of plants have been inoculated in our laboratory. This argues in favor of some ecotype-specific factor involved in the resistance. (ii) Resistance to mechanical inoculation has sometimes been reported for plant viruses (Jones 1993). If these individual plants within susceptible ecotypes are truly virus resistant, further characterization of the resistance would be worthwhile. We have only performed ELISA in noninoculated leaves of these plants, so we cannot discard the possibility that some type of interference with virus systemic movement is occurring. In any case, intra-ecotype variability seems to occur in group II ecotypes.

Four ecotypes showed resistance to TuMV UK-1 in all the inoculated plants (group III ecotypes). Approximately onethird of the plants in ecotypes Di-0, Er-0, and Or- 0 showed an easily detectable level of virus accumulation in the inoculated leaves, but absence of virus in the noninoculated leaves, suggestive of a mechanism of interference with virus long-distance movement, a mechanism also found in $A$. thaliana for TEV, another potyvirus (Mahajan et al. 1998). This and other forms of resistance have been reported several times in A. thaliana for viruses of other taxonomic groups (Callaway et al. 1996; Dempsey et al. 1993; Lartey et al. 1998; Lee et al. 1994, 1996; Leisner and Howell 1992; Martín Martín et al. 1997; Simon et al. 1992; Takahashi et al. 1994; Wang and Simon 1997). As in group II ecotypes, intra-ecotype variability happens in these three ecotypes for the resistance trait.

\section{ACKNOWLEDGMENTS}

This work was funded by grants BIO92-0102 and BIO95-0766C02-01 from the Spanish granting agency CICYT, and ERBCIPACT92-3007 and ERBCHRX-CT93-0170 from the European Commission to F. P. In addition, H. L. C. P. was a CICYT-funded postdoctoral research associate and A. M. M. was a CICYT predoctoral fellow. D. M. H. was partially funded by an INIA predoctoral fellowship and by Novartis Seeds (Sluis and Groot). We thank John Walsh and Carol Jenner from HRI, Wellesbourne, UK, for their generous gifts of TuMV UK-1 isolate, and MAbs to the virus, and Javier Gallego, Carmen Mansilla, and Ernesto Fernández Pareja for their help with electronic image processing.

\section{LITERATURE CITED}

Agrios, G. N. 1997. Plant Pathology. 4th ed. Academic Press, San Diego, CA.

Arroyo, R., Soto, M. J., Martínez-Zapater, J. M., and Ponz, F. 1996. Impaired cell-to-cell movement of potato virus $\mathrm{Y}$ in pepper plants carrying the $y^{\mathrm{a}}\left(p r 2^{1}\right)$ resistance gene. Mol. Plant-Microbe Interact. 9: 314-318.

Brunt, A. A. 1988. Purification of filamentous viruses and virus-induced noncapsid proteins. Pages 85-110 in: The Plant Viruses: The Filamentous Plant Viruses. R. G. Milne, ed. Plenum Press, New York.

Brunt, A. A., Crabtree, K., Dallwitz, M. J., Gibbs, A. J., and Watson, L. 1996. Viruses of Plants. CAB Int., Oxon, U.K.

Callaway, A., Liu, W., Andrianov, V., Stenzler, L., Zhao, J., Wettlaufer, S., Jayakumar, P., and Howell, S. H. 1996. Characterization of cauliflower mosaic virus (CaMV) resistance in virus-resistant ecotypes of Arabidopsis. Mol. Plant-Microbe Interact. 9:810-818.

Carrington, J. C., Jensen, P. E., and Schaad, M. C. 1998. Genetic evidence for an essential role for potyvirus CI protein in cell-to-cell movement. Plant J. 14:393-400.

Cavell, A. C., Lydiate, D. J., Parkin, I. A. P., Dean, C., and Trick, M. 1998. Collinearity between a 30-centimorgan segment of Arabidopsis thaliana chromosome 4 and duplicated regions within the Brassica napus genome. Genome 41:62-69.

Conner, J. A., Conner, P., and Nasrallah, J. B. 1998. Comparative mapping of the Brassica $\mathrm{S}$ locus region and its homeolog in Arabidopsis: Implications for the evolution of mating systems in the Brassicaceae. Plant Cell 10:801-812.

Crute, I. R., Holub, E. B., and Burdon, J. J. 1997. The Gene-for-Gene Relationship in Plant-Parasite Interactions. CAB Int., Oxon, U.K.

Dempsey, D. A., Wobbe, K. K., and Klessig, D. F. 1993. Resistance and susceptible responses of Arabidopsis thaliana to turnip crinkle virus. Phytopathology 83:1021-1029.

Dolja, V. V., Haldeman-Cahill, R., Montgomery, A. E., van den Bosch, K. A., and Carrington, J. C. 1994. Capsid protein determinants involved in cell-to-cell and long distance movement of tobacco etch potyvirus. Virology 206:1007-1016.

Gibb, K. S., Hellmann, G. M., and Pirone, T. P. 1989. Nature of resistance of a tobacco cultivar to tobacco vein mottling virus. Mol. PlantMicrobe Interact. 2:332-339.

Jenner, C. E., and Walsh, J. A. 1996. Pathotypic variation in turnip mosaic virus with special reference to European isolates. Plant Pathol. 45:848-856.

Jones, A. T. 1993. Experimental transmission of viruses in diagnosis. Pages 49-72 in: Diagnosis of Plant Virus Diseases. R. E. F. Matthews, ed. CRC, Boca Raton, FL.

Kasschau, K. D., Cronin, S., and Carrington, J. C. 1997. Genome amplification and long-distance movement functions associated with the central domain of tobacco etch potyvirus helper componentproteinase. Virology 228:251-262.

Koenig, R. 1981. Indirect ELISA methods for the broad specificity detection of plant viruses. J. Gen. Virol. 55:53-62.

Kunkel, B. N. 1996. A useful weed put to work: Genetic analysis of disease resistance in Arabidopsis thaliana. Trends Genet. 12:63-69.

Lartey, R. T., Ghoshroy, S., and Citovsky, V. 1998. Identification of an Arabidopsis thaliana mutation (vsml) that restricts systemic movement of tobamoviruses. Mol. Plant-Microbe Interact. 11:706-709.

Lee, J.-M., Hartman, G. L., Domier, L. L., and Bent, A. F. 1996. Identification and map location of TTR1, a single locus in Arabidopsis thaliana that confers tolerance to tobacco ringspot nepovirus. Mol. Plant-Microbe Interact. 9:729-735.

Lee, S., Stenger, D. C., Bisaro, D. M., and Davis, K. R. 1994. Identification of loci in Arabidopsis that confer resistance to geminivirus infection. Plant J. 6:525-535.

Lehmann, P., Petrzik, K., Jenner, C., Greenland, A., Spâk, J., Kozubek, E., and Walsh, J. A. 1997. Nucleotide and amino acid variation in the coat protein coding region of turnip mosaic virus isolates and possible involvement in the interaction with the Brassica resistance gene TurB01. Physiol. Mol. Plant Pathol. 51:195-208.

Leisner, S. M., and Howell, S. H. 1992. Symptom variation in different Arabidopsis thaliana ecotypes produced by cauliflower mosaic virus. Phytopathology 82:1042-1046.

Leisner, S. M., Turgeon, R., and Howell, S. H. 1992. Long distance movement of cauliflower mosaic virus in infected turnip plants. Mol. 
Plant-Microbe Interact. 5:41-47.

Leisner, S. M., Turgeon, R., and Howell, S. H. 1993. Effects of host plant development and genetic determinants of the long-distance movement of cauliflower mosaic virus in Arabidopsis. Plant Cell 5: 191-202.

Mahajan, S. K., Chisholm, S. T., Whitham, S. A, and Carrington, J. C. 1998. Identification and characterization of a locus (RTM1) that restricts long-distance movement of tobacco etch virus in Arabidopsis thaliana. Plant J. 14:177-186.

Martín Martín, A., Martínez-Herrera, D., Cabrera y Poch, H. L., and Ponz, F. 1997. Variability in the interactions between Arabidopsis thaliana ecotypes and oilseed rape mosaic tobamovirus. Aust. J. Plant Physiol. 24:275-281.

Martínez-Herrera, D., Romero, J., Martínez-Zapater, J. M., and Ponz, F. 1994. Suitability of Arabidopsis thaliana as a system for the study of plant-virus interactions. Fitopatología 29:132-136.

Nicolas, O., Dunnington, S. W., Gotow, L. F., Pirone, T. P., and Hellmann, G. 1997. Variations in the VPg protein allow a potyvirus to overcome $v a$ gene resistance in tobacco. Virology 237:452-459.

Nolasco, G., de Blas, C., Torres, V., and Ponz, F. 1993. A combination of immunocapture and PCR amplification in a microtiter plate for the routine detection of plant viruses and subviral pathogens. J. Virol. Methods 45:201-218.

Riechmann, J. L., Laín, S., and García, J. A. 1992. Highlights and prospects of potyvirus molecular biology. J. Gen. Virol. 73:1-16.

Roberts, I. M., Wang, D., Findlay, K., and Maule, A. J. 1998. Ultrastructural and temporal observations of the potyvirus cylindrical inclusions (CIs) show that the CI protein acts transiently in aiding virus movement. Virology 245:173-181.

Rodríguez-Cerezo, E., Findlay, K., Shaw, J. G., Lomonossoff, G. P., Qiu, S. G., Linstead, P., Shanks, M., and Risco, C. 1997. The coat and cylindrical inclusion proteins of a potyvirus are associated with connections between plant cells. Virology 236:296-306.

Rojas, M. R., Zerbini, F. M., Allison, R. F., Gilbertson, R. L., and Lucas, W. J. 1997. Capsid and helper component proteins function as potyvirus cell-to-cell movement proteins. Virology 237:283-295.

Sambrook, J., Fritsch, E. F., and Maniatis, T. A. 1989. Molecular Clon- ing. A Laboratory Manual. 2nd ed. Cold Spring Harbor Laboratory, Cold Spring Harbor, NY.

Sánchez, F., Martínez-Herrera, D., Aguilar, I., and Ponz, F. 1998. Infectivity of turnip mosaic potyvirus cDNA clones and transcripts on the systemic host Arabidopsis thaliana and local lesion hosts. Virus Res. 55:207-219.

Schaad, M. C., Lellis, A. D., and Carrington, J. C. 1997. VPg of tobacco etch potyvirus is a host genotype-specific determinant for longdistance movement. J. Virol. 71:8624-8631.

Shukla, D. D., Ward, C. W., and Brunt, A. A. 1994. The Potyviridae. CAB Int., Oxon, U.K.

Simon, A. E., Li, X. H., Lew, J. E., Stange, R., Zhang, C., Polacco, M., and Carpenter, C. D. 1992. Susceptibility and resistance of Arabidopsis thaliana to turnip crinkle virus. Mol. Plant-Microbe Interact. 5: 496-503.

Takahashi, H., Goto, N., and Ehara, Y. 1994. Hypersensitive response in cucumber mosaic virus-inoculated Arabidopsis thaliana. Plant J. 6: 369-377.

Tomlinson, J. A. 1987. Epidemiology and control of virus diseases of vegetables. Ann. Appl. Biol. 110:661-681.

Tomlinson, J. A., and Ward, C. M. 1978. The reactions of swede (Brassica napus) to infection by turnip mosaic virus. Ann. Appl. Biol. 89:61-69.

Valkonen, J., and Somersalo, S. 1996. Patterns and barriers of cell-tocell movement of tobacco etch potyvirus (TEV-GUS) in Solanum brevidens. Plant Sci. 113:221-228.

Wang, K. Q., and Simon, A. E. 1997. Satellite RNA-mediated resistance to turnip crinkle virus in Arabidopsis involves a reduction in virus movement. Plant Cell 9:2051-2063.

Wittmann, S., Chatel, H., Fortin, M. G., and Laliberté, J. F. 1997. Interaction of the viral protein genome linked of turnip mosaic potyvirus with the translational eukaryotic initiation factor (iso) 4E of Arabidopsis thaliana using the yeast two hybrid system. Virology 234:84-92.

Yoshii, M., Yoshioka, N., Ishikawa, M., and Naito, S. 1998. Isolation of an Arabidopsis thaliana mutant in which the multiplication of both cucumber mosaic virus and turnip crinkle virus is affected. J. Virol. $72: 8731-8737$ 